\title{
Implementation of Krill Herd Algorithm for Optimal Sizing and Placing of DG in Radial Distribution System
}

\author{
Ponnapureddy Niveditha ${ }^{1}$, M. S Sujatha ${ }^{2}$ and M. Vijaya Kumar ${ }^{3}$ \\ ${ }^{1}$ PG Scholar, EEE, Applied Renewable Energy Research Lab, \\ Sree Vidyanikethan Engineering College, India \\ ${ }^{2}$ Professor, EEE, Applied Renewable Energy Research Lab, \\ Sree Vidyanikethan Engineering College, India \\ ${ }^{3}$ Professor, EEE, JNTUA, Anantapuram, India \\ 1niveponnapureddy479@gmail.com, ${ }^{2}$ sujatha.machineni@gmail.com
}

\begin{abstract}
In the electric power systems, the role of Distributed Generation $(D G)$ is playing a key role, but the selection and sizing of DG is a challenging issue. In the literature many algorithms are available, each having its own advantages and disadvantages. Krill Herd Algorithm (KHA) is one of the nature inspired intelligent algorithm, which consider the herding behaviour of the krill individual for simulation. It has been utilized to solve many optimization problems in different fields and shown to be most efficient. In this paper Krill Herd Algorithm is used for optimal placing and sizing of DG in a radial distribution system for reduction of losses and improvement of voltage profile by considering the various constrains like DG real power limit, DG location Constraint, voltage limit and power balance constraint. The proposed algorithm is implemented on IEEE 33-bus test system. The results of the base case are compared with GA and Krill Herd Algorithms.
\end{abstract}

Key words: Placement of DG, Radial Distribution system, Genetic Algorithm, Krill Herd Algorithm

\section{Introduction}

Distributed Generation (DG) power on-site rather than centrally eliminates the cost, complexity, interdependencies and inefficiencies associated with transmission and distribution. The different types of Distributed Generation (DG) technologies are Reciprocating Diesel or Natural Gas Engines, Micro-Turbines, Combustion Gas Turbines, Fuel Cells, Photovoltaic (PV) system, Wind Turbines. The common DG systems in the residential sector are solar photovoltaic panels, small wind turbines, and Natural-gas-fired fuel cells, Emergency backup generators, usually fuelled by the diesel fuel or gasoline. The DG can include resources in the commercial and industrial sector such as wind, hydropower, solar photovoltaic panels, biomass combustion, combined heat and power systems reciprocating combustion engines etc. The optimal sizing and placement of DG in a radial distribution system is very important. There is variety of benefits by the placement of DG. It reduces the real and reactive power losses, voltage profile improvement, and network reliability. There are different techniques used for the optimal allocation and sizing of DG in a radial distribution system.

Analytical method is used for the optimal allocation and sizing of DG in a radial distribution system for minimization of power losses of the system [1, 2, 3]. The advantages of analytical method are it uses Self Correction Algorithm (SCA) which uses less number of iterations to achieve convergence and hence demand less computation

Received (April 15, 2018), Review Result (July 25, 2018), Accepted (August 11, 2018) 
time and for larger systems the total number of load flows used normally remains unchanged. The drawback of this method is it is no applicable for unbalanced and meshed distribution system. Firefly Algorithm is a meta-heuristic technique used for the optimal allocation and sizing of DG in radial distribution system which is inspired by the flashing behaviour of flies [4]. The advantages of the algorithm is the losses get reduced, voltage profile improvement and minimum generation cost. The drawback of the algorithm is slow convergence. Bacterial Foraging Optimization Algorithm (BFOA) is a swarm intelligence technique used for the minimization of network power losses, improving voltage stability and operational cost [5]. The proposed technique is very accurate in finding the optimum solutions and this work can also be implemented for all systems with $n$ number of buses and all types of loads. The drawback of the BFOA is the complication of the algorithm and hence less convergence speed. Invasive Weed Optimization (IWD) is a population based meta-heuristic algorithm based on the behaviour of weeds [6]. The main advantage of the proposed technique is that it is easy to implement and capable of finding feasible. The drawback of this algorithm is the results are near optimal. In determining the optimal sizing of DG and identifying the switching operation plan for network reconfiguration, an optimization method which is called as Rank Evolutionary Particle Swarm Optimization (REPSO) will be introduced [7]. The objective is to minimize the total power losses in a radial distribution network and to find the size of DG. The drawback of the REPSO is poor convergence speed. The allocation of optimally distributed generation is carried out by using GA for minimum system losses in radial distribution networks [8, 9, 10 and 11]. The distributed generation is one of the possible options for mitigation of problems of load growth, overloading of lines, quality of supply and reliability, in turn extending equipment maintenance intervals and to reduce line losses. Therefore, this paper aims to minimize active power loss by placing DG in a radial distribution system. The loss sensitivity to active power injection at various nodes is used to decide the strategic locations. The optimum location and size of DG have created collision on voltage profile, system power losses, and voltage stability. In this work, the Whale Optimization Algorithm technique is considered with a multi-objective function to determine the location and size of DG [12]. The algorithm can find the solutions with better quality for more extensive systems computational efficiency. ABC (Artificial Bee Colony) Algorithm has been used for the optimal allocation and sizing of DG in a Radial Distribution System (RDS). It uses only two parameters for tuning. The algorithm is used for mixed-integer problems and unconstrained problems [13, 14]. Various Optimization methods for optimal placement of DG to reduce the losses is discussed in [15].

The main drawbacks of above all methods are poor convergence speed and some are not applicable for meshed and unbalanced distribution system. To overcome the above drawbacks the paper aim to implement a new nature inspired heuristic technique, Krill Herd Algorithm for solving the DG placement problem with power loss reduction and voltage profile improvement as objective function subjected to various constraints. Both GA and Krill Herd Algorithms are applied on 33-bus IEEE standard test system with various load conditions and multiple DGs. The results of KHA are compared with GA and Base case. The paper is organised as follows Abstract, (1) Introduction (2) Problem Formulation (3) Genetic Algorithm (4) Krill Herd Algorithm (5) Algorithm for KHA (6) IEEE 33-bus test system (7) Results and Discussions (8) Conclusion and (9) References.

\section{Problem Formulation}

\subsection{Load Flow Equations}

Due to high R/X value, Gauss Seidal and Newton-Raphson are not suited for finding the solution to a Radial Distribution System. The current summation method which 
consists of forward and backward [16, 17] sweep are used finding power flow in the system.

\subsection{RDS Load Flow Method Steps:}

1. Read the line data and load data.

2. Set the flat voltage profile 1 p.u. for all the buses.

3. Calculate the injected power at node $\mathrm{i}, S^{i}=P^{i}+j Q^{i}$ for $\mathrm{i}=1$ to $\mathrm{n}$

Where $n=$ number of nodes

4. Set iteration count iteration $=1$ and to maximum iterations.

5. We know that $\mathrm{S}=\mathrm{VI}^{*}$

$$
\begin{gathered}
I^{*}=\frac{S}{V} \\
I=\left[\frac{S}{V}\right]^{*}
\end{gathered}
$$

6. By using the above equation calculate bus current. The bus current a node $\mathrm{i}$ and iteration=iter is given by

$$
I^{i e r, i}=\left[\frac{S^{i}}{V^{(i t e r-1), i}}\right]
$$

Where

$$
\begin{aligned}
& S^{i}=\text { injected power at node ' } \mathrm{i} \text { ' } \\
& \left.V^{(i t e r-1), i}=\text { Voltage at node i at (iter-1 }\right)^{\text {th }} \text { iteration }
\end{aligned}
$$

7. Backward sweep: In this step, the load current of each node of a distribution network having $\mathrm{N}$ number of nodes is determined as:

$$
\bar{I}_{L}(m)=\left\{\frac{P_{L}(m)-j Q_{L}(m)}{\overline{V^{*}}(m)}\right\} \quad\lceil m=1,2,3 \ldots \ldots N\rceil
$$

Calculate the branch current by using the below equation

$$
\bar{I}_{L}(m n)=\bar{I}_{L}(n)+\sum_{m \in r} \bar{I}_{L}(m)
$$

Where $\mathrm{m}$ represents the sending end and $\mathrm{n}$ represents the receiving end

8. Forward sweep: This step is used after the backward sweep so as to determine the voltage at each node of a distribution network as follows:

$$
\bar{V}(m n)=\bar{V}(m)-\bar{I}(m n) \bar{Z}(m n)
$$

\section{Genetic Algorithm}

Genetic Algorithm (GA) is the heuristic search algorithm based on the evolutionary ideas of natural selection and genetics. It is an intelligent exploitation of a random search 
used to solve optimization problems. The basic techniques of the GAs are intended to simulate processes in natural system necessary for evolution, especially those that follow the principles first laid down by Charles Darwin, "survival of the fittest," because in nature, competition among individuals for scarce resources results in the fittest individuals dominating over the weaker ones. GAs provides more benefits over typical optimization techniques such as linear programming, heuristic, and depth-first. The basic terminologies in Genetic Algorithm are individual, genes, fitness, and population. The operators in GA are Encoding, Selection, Crossover and Mutation [19].

\subsection{Flow chart for Genetic Algorithm}

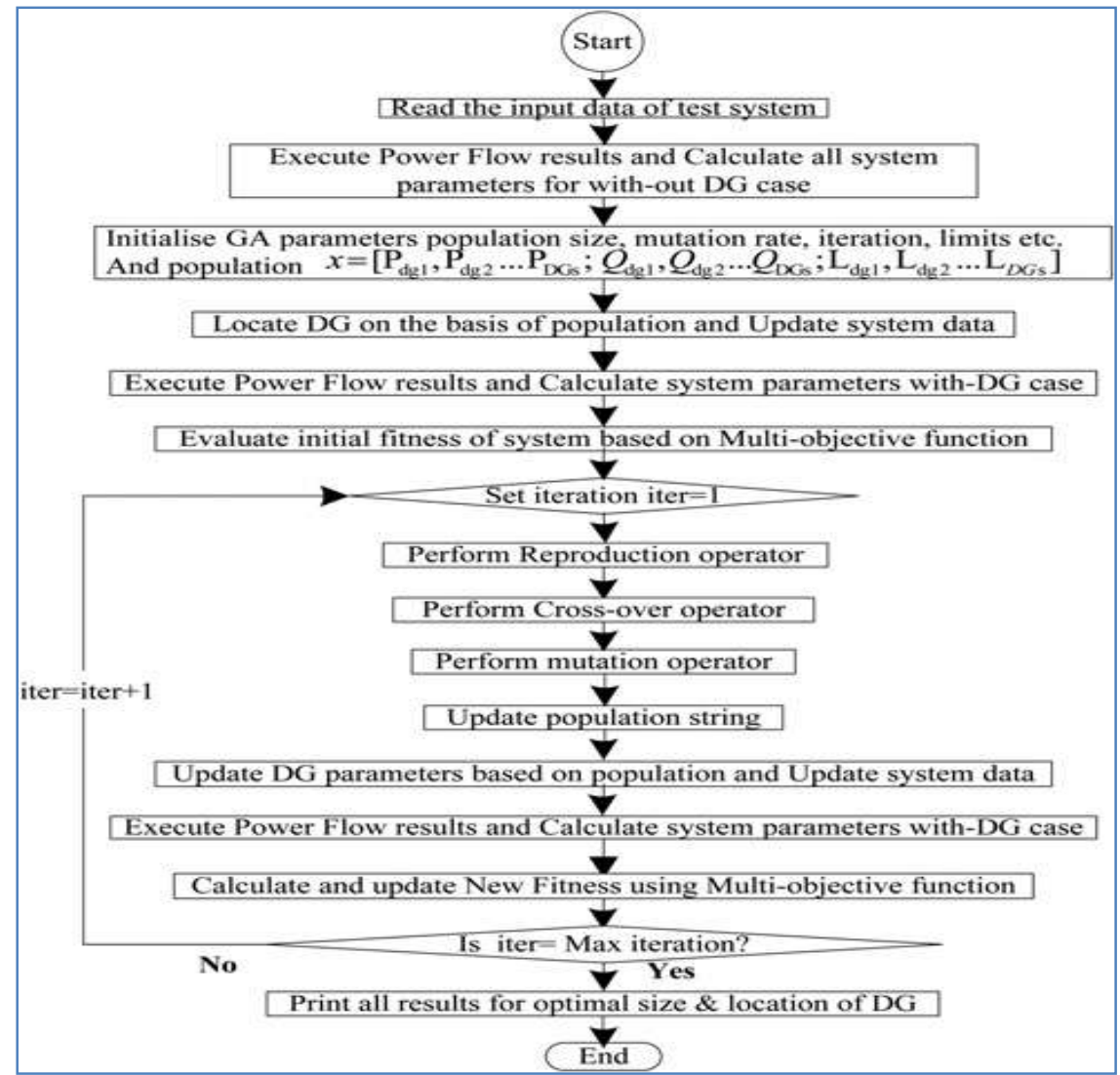

\section{Krill Herd Algorithm}

Krill herd $(\mathrm{KH})$ is a novel meta-heuristic swarm intelligence optimization method for solving optimization problem, which is based on the herding behaviour of the krill individuals. The position of individual krill is determined by the following three steps [20].

1) Movement induced by the other krill individuals

2) Foraging activity

3) Physical diffusion

The Lagrangian model used for krill Herd (KH) [18] is

$$
\frac{d X_{m}}{d t}=N_{m}+F_{m}+D_{m}
$$


Where $N_{m}$ the Movement is induced by other krill individuals, $F_{m}$ is the Foraging Activity and $D_{m}$ is the Physical Diffusion of the $m$-th krill individual.

\subsection{Movement induced by other Krill Individuals:}

The distance from food and highest density of swarm is defined as the fitness function for each krill individual. Here for a krill individual, the motion induced by other krill individuals is represented in a mathematical form as follows:

$$
N_{m}^{\text {new }}=N^{\mathrm{max}} \theta_{m}+\omega_{n} N_{m}^{\text {old }}
$$

Where

$N^{\text {max }}=$ Maximum induced speed in $\mathrm{ms}^{-1}$

$\omega_{n}=$ Inertia weight of the motion induced, in the range of $(0,1)$

$N_{m}^{\text {old }}=$ is the last motion induced

The motion induced for the direction $\theta_{m}$ is approximate from the local effect, a target effect and a repulsive effect. Then $\theta_{m}$ is represented by the below equation

$$
\theta_{m}=\theta_{m}^{\text {local }}+\theta_{m}^{\text {arget }}
$$

Where

$\theta_{m}^{\text {local }}=$ is the local effect provided by the neighbours

$\theta_{m}^{t \text { arget }}=$ the best krill individual which has a effect provided by the target direction

Now the effect of neighbours can be given as shown in the below equations

$$
\theta_{m}^{\text {local }}=\sum_{n=1}^{N N} \hat{K}_{m n} \hat{X}_{m n}
$$

Where

$$
\begin{gathered}
\hat{X}_{m n}=\frac{X_{n}-X_{m}}{\left\|X_{n}-X_{m}\right\|+\varepsilon} \\
\hat{K}_{m n}=\frac{K_{m}-K_{n}}{K^{\text {worst }}-K^{\text {best }}}
\end{gathered}
$$

Where

$\mathrm{NN}=$ Number of neighbours

$K_{m}=$ the m-th krill individual with a fitness value (i=1 to $\mathrm{nk}$ )

$K_{n}=$ fitness value of the neighbour ( $\mathrm{j}=1$ to $\mathrm{NN}$ )

$\varepsilon=$ A small positive number

$\mathrm{X}=$ related position of the krill individual

$K^{\text {worst }}$ and $K^{\text {best }}$ are worst and best fitness values of the krill individual 
The best fitness on the $i$ th individual krill is taken into account using the below equation

$$
\theta_{m}^{t \arg e t}=C^{b e s t} \hat{K}_{m, \text { best }} \hat{X}_{m, \text { best }}
$$

Where, $C^{\text {best }}$ is the effective coefficient of the krill individual with the best fitness to the $\mathrm{m}$-th krill individuals. The target should be more effective than other krill individuals such as neighbours and the value is given as

$$
C^{\text {best }}=2\left(\operatorname{rand}+\frac{I}{I_{\max }}\right)
$$

Where

rand $=$ random number between $\mathrm{o}$ and 1

I = actual iteration count

$I_{\max }=$ maximum iteration count

The krill individual has a sensing distance which is represented by the below mathematical equation

$$
d_{s, m}=\frac{1}{5 N} \sum_{n=1}^{N}\left\|X_{m}-X_{n}\right\|
$$

The equation for the movement induced by the other krills can be represented by the below mathematical formula

$$
N_{m}^{\text {new }}=\left[N^{\max }\left\{\sum_{n=1}^{N N}\left[\frac{K_{m}-K_{n}}{K^{\text {worst }}-K^{\text {best }}}\right]\left[\frac{X_{n}-X_{m}}{X_{n}-X_{m}+\varepsilon}\right]\right\} *\left\{2\left(\operatorname{rand}+\frac{I}{I_{\max }}\right) \hat{K}_{m, \text { best }} \hat{X}_{m, b e s t}\right)\right]+\omega_{n} N_{m}^{\text {old }}
$$

\subsection{Foraging Activity:}

The foraging motion mainly depends on two parameters, one is food location and the second is previous experience about the food location. The foraging motion for the $\mathrm{m}$-th krill individual can be expressed by the below equation:

$$
F_{m}=V_{f} \lambda_{m}+\omega_{f} F_{m}^{\text {old }}
$$

Where

$$
\begin{aligned}
& V_{f}=\text { foraging motion } \\
& \omega_{f}=\text { inertia weight of the foraging motion in the range of }(0,1) \\
& F_{m}^{\text {old }}=\text { is the last foraging motion }
\end{aligned}
$$

The food attraction in the mathematical model is given as

$$
\lambda_{m}=\lambda_{m}^{\text {food }}+\lambda_{m}^{\text {best }}
$$

Where

$$
\begin{aligned}
& \lambda_{m}^{\text {food }}=\text { is the food attractive } \\
& \lambda_{m}^{\text {best }}=\text { is the effect of the best fitness of the } i \text { th krill so far }
\end{aligned}
$$


The food attraction for the $i$ th krill individual can be determined as follows:

$$
\lambda_{m}^{\text {food }}=C^{\text {food }} \hat{K}_{m, \text { food }} \hat{X}_{m, \text { food }}
$$

Where

$$
C^{\text {food }}=\text { is the food coefficient }
$$

The krill herding decreases according to the time due to the effect of food, the coefficient is given by the following equation

$$
C^{\text {food }}=2\left(1-\frac{I}{I_{\max }}\right)
$$

So substituting the equation (12) in equation (11) we get

$$
\lambda_{m}^{\text {food }}=2\left(1-\frac{I}{I_{\max }}\right) \hat{K}_{m, \text { food }} \hat{X}_{m, \text { food }}
$$

The following equation gives the best fitness effect of the $\mathrm{i}^{\text {th }} \mathrm{krill}$ individual

$$
\lambda_{m}^{\text {food }}=\hat{K}_{m, \text { best }} \hat{X}_{m, \text { best }}
$$

Now the basic equation for the foraging activity is given by the following equation

$$
F_{m}=V_{f}\left\{2\left(1-\frac{I}{I_{\max }}\right) \hat{K}_{m, \text { food }} \hat{X}_{m, \text { food }}+\hat{K}_{m, \text { best }} \hat{X}_{m, \text { food }}\right\}+\omega_{f} F_{m}^{\text {old }}
$$

\subsection{Physical Diffusion}

The krill individual is considered to be in a random process. The diffusion speed and random directional vector for the motion can be given by the following equation:

$$
D_{m}=D^{\max }\left(1-\frac{I}{I_{\max }}\right) \delta
$$

Where

$$
\begin{aligned}
& D^{\max } \text { - Maximum diffusion speed, } D^{\max } \in[0.01,0.02] \mathrm{ms}^{-1} \\
& \delta \quad \text { - Random directional vector }[-1 \& 1]
\end{aligned}
$$

\subsection{Motion Process of Krill Herd}

The motion induced by other krill individuals and the foraging activity contains two global and two local strategies [21]. This two work in a parallel operation which make $\mathrm{KH}$ powerful. The motion vector is given by the following equation

$$
X_{m}(t+\Delta t)=X_{m}(t)+\Delta t \frac{d X_{m}}{d t}
$$

Where

$$
\Delta t=C_{t} \sum_{n=1}^{N V}\left(U B_{n}-L B_{n}\right)
$$


$\mathrm{NV}$ - total number of variables

UB \& LB - upper and lower bounds of the variables

$$
C_{t} \text { - Constant between }[0,2]
$$

\subsection{Genetic Operators}

1. Crossover

$$
\begin{gathered}
X_{m, i}=X_{r, m} \quad \operatorname{rand}_{m, i}<C_{r} \\
\text { Else } X_{m, i}=X_{m, i}
\end{gathered}
$$

Where $C_{r}=0.2 \hat{K}_{m, b e s t}$ and $\mathrm{r} \in\{1,2, \ldots \ldots \mathrm{i}-1, \mathrm{i}+1 \ldots \ldots \mathrm{N}\}$

2. Mutation

$$
\begin{gathered}
X_{m, i}=X_{k b e s t, i}+\left(X_{s, m}-X_{t, m}\right) \quad \operatorname{rand}_{m, i}<M u \\
\text { Else } X_{m, i}=X_{m, i}
\end{gathered}
$$

Where $M u=\frac{0.05}{\hat{K}_{m, \text { best }}}$ and $\mathrm{s}, \mathrm{t} \in 1,2 \ldots \mathrm{m}-1, \mathrm{~m}+1 \ldots \ldots \mathrm{K}$

\section{Algorithm for Krill Herd}

Step 1: Read the system data and initialize the KH parameters. Now define the maximum iteration count as $I_{\max }$

Step 2: Set iter $=1$.

Step 3: Run load flows and find the system losses and detect all the krill according to the fitness.

Step 4: Perform the three operations for all the krills such as
1) Movement induced by other krill individuals
2) Foraging Activity
3) Physical Diffusion

Step 5: Choose the best krill for mating.

Step 6: Generate a new krill $X_{i}^{\prime}$ by applying crossover.

Step 7: Find the fitness.

Step 8: Accept the new generated solution $X_{i}^{\prime}$ as $X_{i}^{\prime}+1$.

Step 9: Update the krill position by equation (17) as $X_{i}^{\prime}+1$.

Step 10: Set iter $=$ iter+1.

Step 11: Go to step 3 until it is equal to $I_{\max }$

Step 12: Stop. 


\section{IEEE-33 Bus Test Systems}

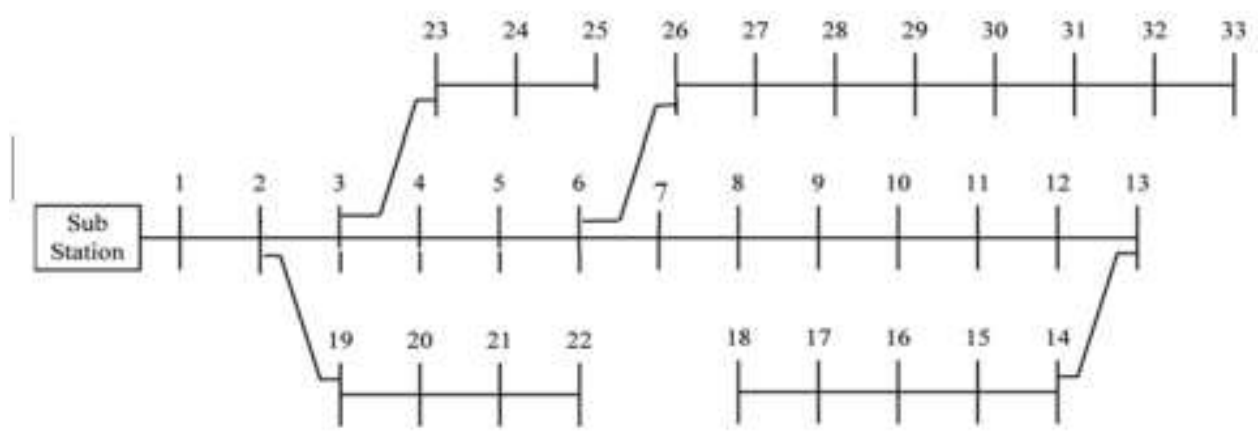

Figure 1. Single Line Diagram of IEEE-33 Bus Test System

\section{Results and Discussions}

Genetic and Krill Herd Algorithms are implemented on the IEEE 33-bus radial distribution system and compared the results. Programming is developed using MATLAB 2014a environment. Various constraints are considered and are common for any number of DGs, but the number of DGs is limited to three from the reliability point of view [22]. Bus-1 is taken as slack bus for the test system. The load variation is considered as nominal (1.0), light (0.5) and peak load (1.6) at full load condition and the results are tabulated.

The single line diagram of 33-bus radial distribution system is shown in Figure 1. The total losses of uncompensated system are $202.65 \mathrm{~kW}$ and the voltage profile is 0.9131 P.u. The main objective of this paper is to minimize the losses and improve the voltage profile. The proposed Krill Herd Algorithm is used to find the optimal location and size of DG; obtained results are shown in Table 3. The optimal locations of multi-DGs are 18, 32, and 33 and optimal sizes are 870,890 and 830 for KHA. The locations and size of multi-DG for GA are $18,32, \& 33$ and $950,890, \& 850$ respectively.

The active and reactive power losses without DG are $202.65 \mathrm{~kW}$ and $135.13 \mathrm{KVAr}$, DG-GA is $86.28 \& 64.46$ and DG-KHA is $81.82 \& 60.96$ respectively shown in Table 1 . The results show that the overall loss reduction with-DG using KHA is efficient technique. The voltage profile without DG is 0.9131 P.u, DG-GA is 0.9700 P.u and for DG-KHA is 0.9710 p.u. is shown is Table 2. From the results it is evident that proposed Krill Herd Algorithm is better than Genetic Algorithm.

Figure 2 illustrates the improvement of voltage profile with respect to number of buses for Base case, GA and KHA. Figure 3 and Figure 4 show the graphical representation of real and reactive power losses for different cases. By observing the results, the losses are reduced after placement of DG. The graphical representation of active power losses, reactive power losses and voltage profile with single DG, Two DG and Three DG are given in Figure 5, Figure 6 and Figure 7 respectively. The results show that losses are reduced and voltage profile is improved for multi-DG. The performance of the system at different load levels is given in Table 4. 


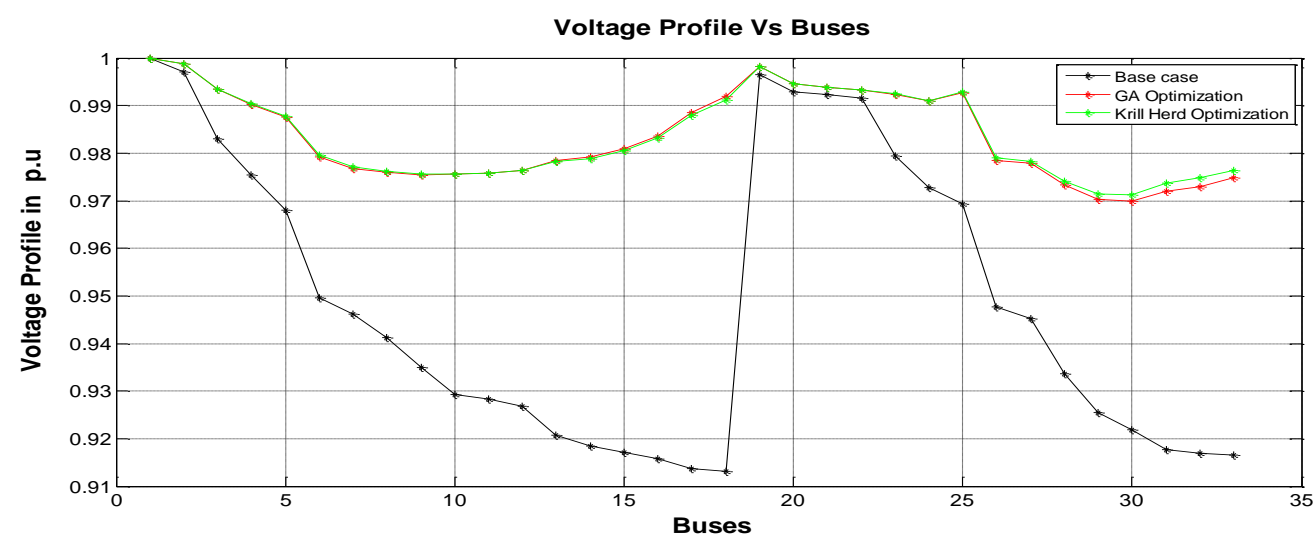

Figure 2. Comparison of Voltage Profile for Base case, GA and KHA

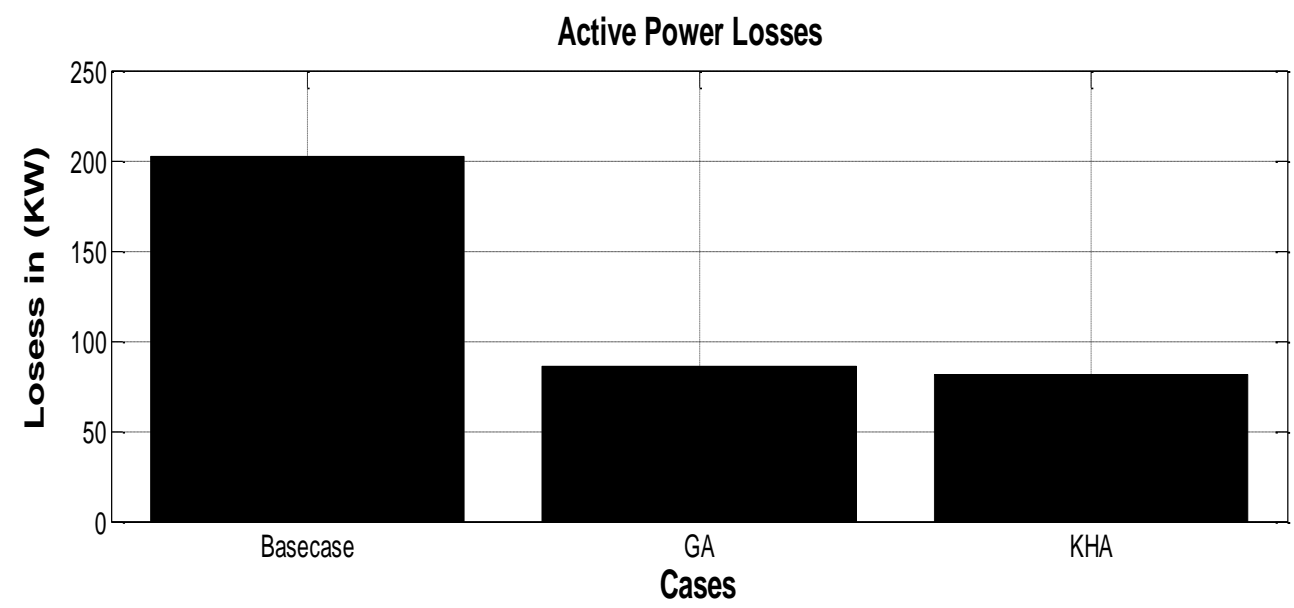

Figure 3. Comparison of Active Power Losses for Base Case, GA and KHA

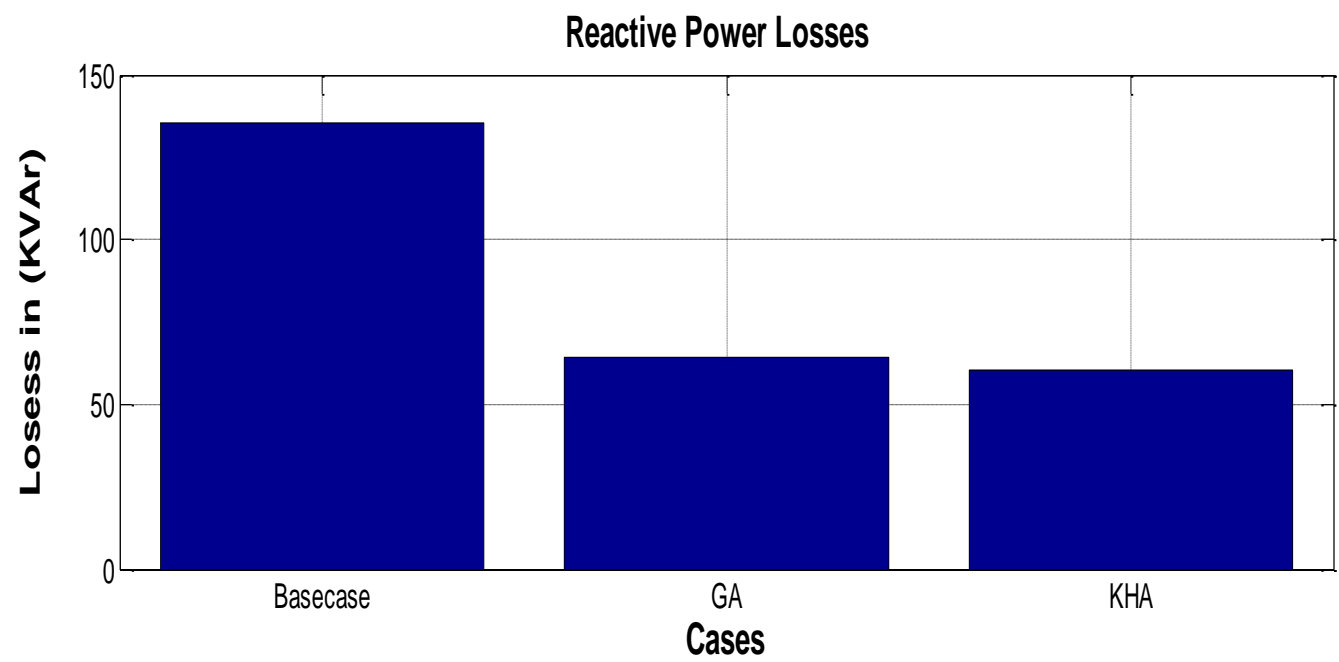

Figure 4. Comparison of Reactive Power Losses for Base Case, GA and KHA 


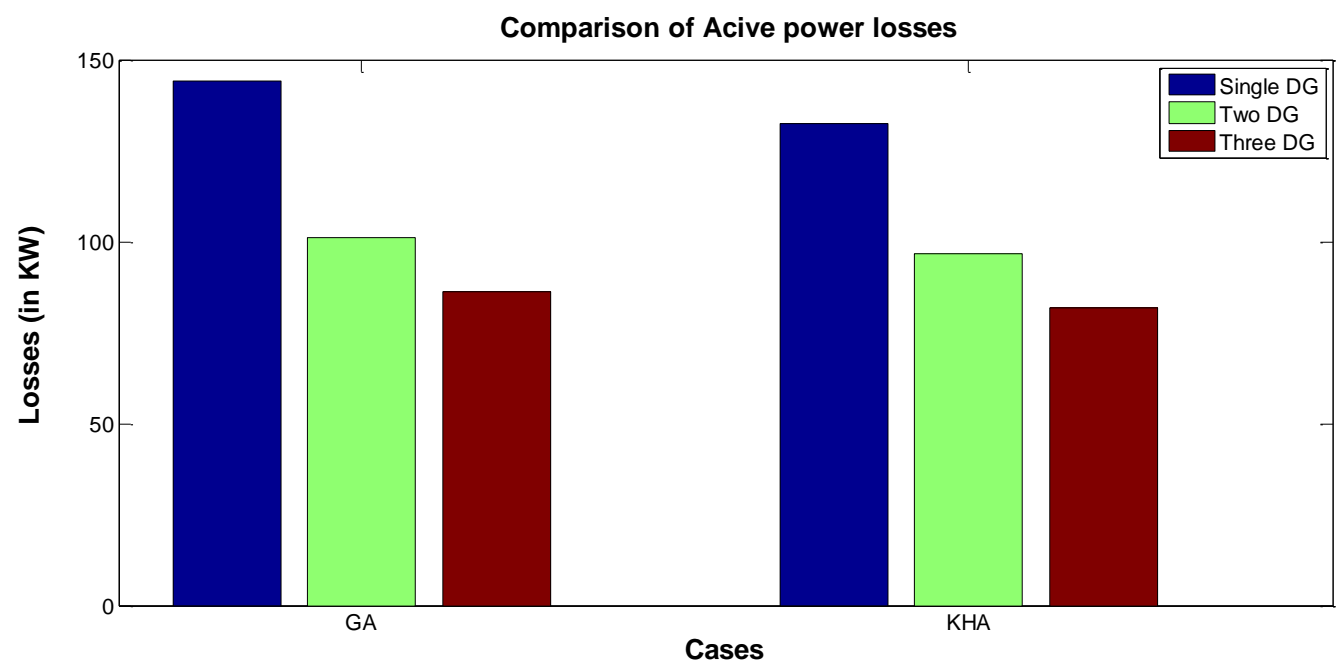

Figure 5. Comparison of Active Power Losses

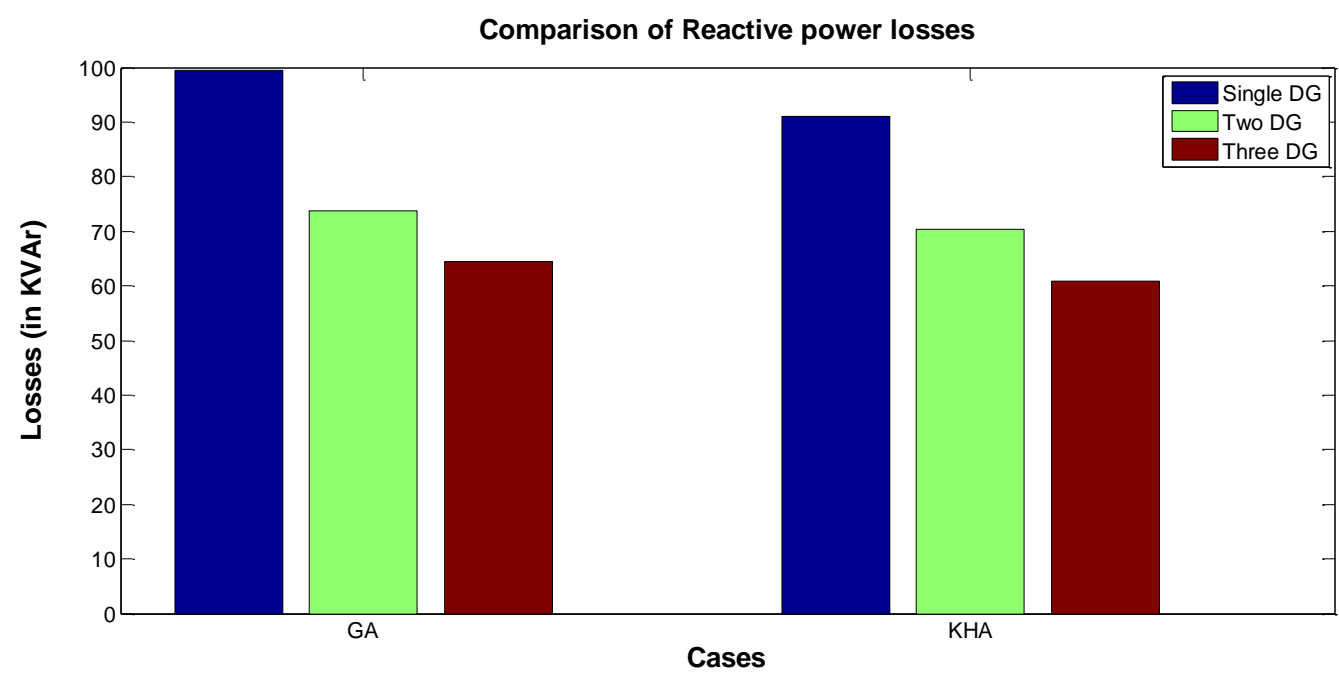

Figure 6. Comparison of Reactive Power Losses

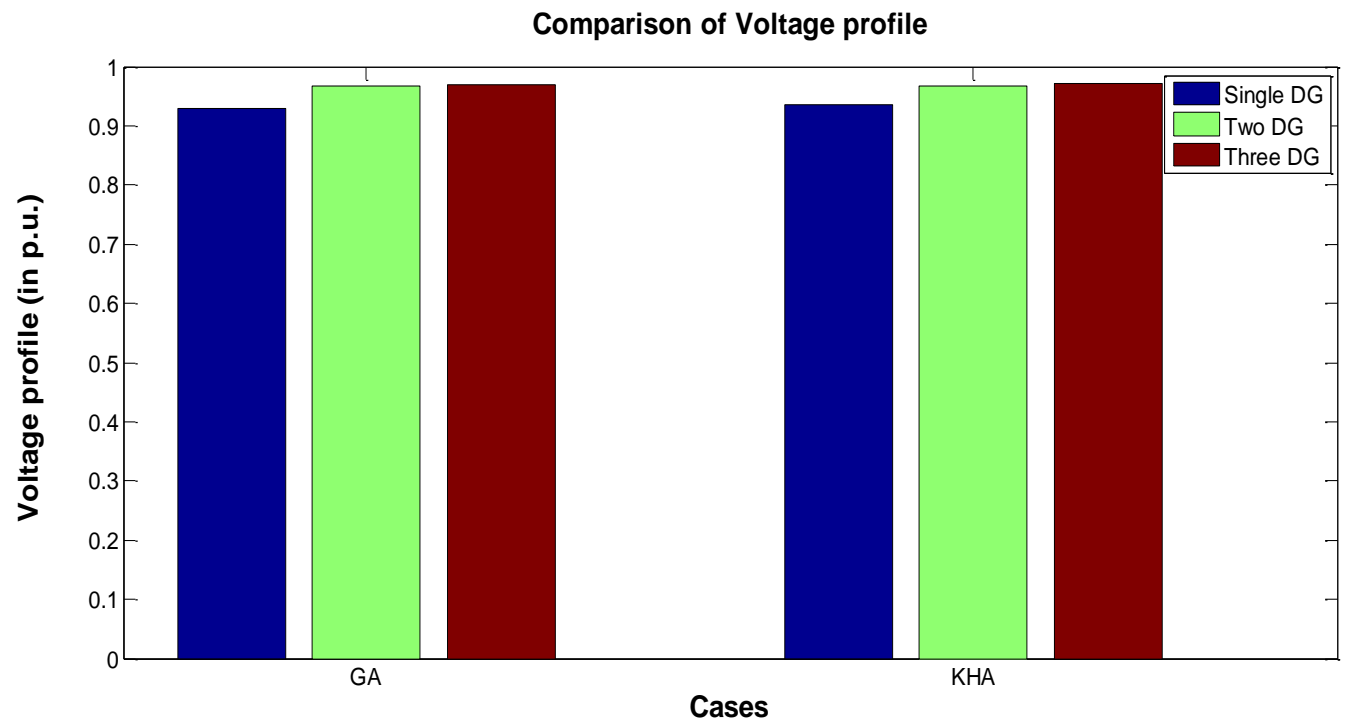

Figure 7. Comparison of Voltage Profile 
Table 1. Active and Reactive Power Losses for 33-bus System

\begin{tabular}{|c|c|c|c|}
\hline Type & NO-DG & DG-GA & DG-KHA \\
\hline Real power losses (KW) & 202.65 & 86.28 & 81.82 \\
\hline Reactive power losses (KVAr) & 135.13 & 64.46 & 60.96 \\
\hline
\end{tabular}

Table 2. Voltage Profile of 33-bus System with NO-DG, DG-GA and DG-KHA

\begin{tabular}{|c|c|c|c|}
\hline Type & NO-DG & DG-GA & DG-KHA \\
\hline Voltage profile & 0.9131 & 0.9700 & 0.9710 \\
\hline
\end{tabular}

Table 3. Summary of Results for Multiple DG with GA and KHA for 33-bus System

\begin{tabular}{|c|c|c|c|c|c|c|}
\hline \multirow[t]{2}{*}{ Type } & \multicolumn{3}{|c|}{ Genetic Algorithm } & \multicolumn{3}{|c|}{ Krill Herd Algorithm } \\
\hline & $\begin{array}{l}\text { Single } \\
\text { DG }\end{array}$ & $\begin{array}{l}\text { Two } \\
\text { DG }\end{array}$ & $\begin{array}{l}\text { Three } \\
\text { DG }\end{array}$ & $\begin{array}{l}\text { Single } \\
\text { DG }\end{array}$ & $\begin{array}{l}\text { Two } \\
\text { DG }\end{array}$ & $\begin{array}{c}\text { Three } \\
\text { DG }\end{array}$ \\
\hline $\begin{array}{l}\text { Optimal Bus no./ } \\
\text { DG Size in KW }\end{array}$ & $33 / 850$ & $\begin{array}{l}33 / 850 \\
18 / 950\end{array}$ & $\begin{array}{l}33 / 850 \\
18 / 950 \\
32 / 890\end{array}$ & $33 / 830.00$ & $\begin{array}{l}33 / 830 \\
18 / 870\end{array}$ & $\begin{array}{l}33 / 830 \\
18 / 870 \\
32 / 890\end{array}$ \\
\hline $\begin{array}{l}\text { Real power losses } \\
\text { (KW) }\end{array}$ & 144.23 & 101.11 & 86.28 & 132.34 & 96.66 & 81.82 \\
\hline $\begin{array}{l}\text { Reactive power } \\
\text { losses (KVAr) }\end{array}$ & 99.45 & 73.77 & 64.46 & 90.96 & 70.26 & 60.96 \\
\hline Voltage (p.u.) & 0.9297 & 0.9668 & 0.9700 & 0.9150 & 0.9679 & 0.9710 \\
\hline
\end{tabular}

Table 4. Real and Reactive Power Losses Comparison using GA and KHA with Load Variation

\begin{tabular}{|c|c|c|c|c|c|c|}
\hline Type & \multicolumn{3}{|c|}{ Genetic Algorithm } & \multicolumn{3}{c|}{ Krill Herd Algorithm } \\
\hline & $\begin{array}{c}\text { Light } \\
\text { load (0.5) }\end{array}$ & $\begin{array}{c}\text { Nominal } \\
\text { load(1.0) }\end{array}$ & $\begin{array}{c}\text { Peak load } \\
(1.6)\end{array}$ & $\begin{array}{c}\text { Light load } \\
(0.5)\end{array}$ & $\begin{array}{c}\text { Nominal } \\
\text { load(1.0) }\end{array}$ & $\begin{array}{c}\text { Peak load } \\
(1.6)\end{array}$ \\
\hline $\begin{array}{c}\text { Real power losses } \\
\text { (KW) }\end{array}$ & 20.72 & 86.28 & 233.09 & 33.04 & 176.12 & 506.56 \\
\hline $\begin{array}{c}\text { Reactive power } \\
\text { losses (KVAr) }\end{array}$ & 15.47 & 64.46 & 174.32 & 21.69 & 116.69 & 336.62 \\
\hline Voltage (p.u.) & 0.9853 & 0.9700 & 0.9506 & 0.8642 & 0.9219 & 0.9677 \\
\hline
\end{tabular}

\section{Conclusion}

The optimal allocation and sizing of multi-DG using GA and KHA are analysed for IEEE 33-bus radial distribution system. The proposed algorithm is applied at different 
load levels with single and multi-DGs and the results obtained show the effectiveness of the algorithm. The results illustrate that the real and reactive power losses in the system are reduced and improve the voltage profile by including DGs. From the results it is considered that Krill Herd Algorithm can more comfortably use for solving the optimal DG placement problems in radial distribution systems. Hence it can be concluded that proposed algorithm provides better technical and economical benefits compared with existing approaches.

\section{References}

[1] R. Viral and D. K. Khatod, "An analytical approach for sizing and siting of DGs in balanced radial distribution networks for loss minimization”, Electra. Power Energy Syst., vol. 67, (2015), pp. 191-201.

[2] A. Lakshmi Devi and A. Chaithanya, "A New Analytical Method for the sizing and siting of DG in Radial System of Minimize Real Power Losses", International Journal of Computational Engineering Research, vol. 2, no. 7, (2012).

[3] N. Ramya and T. Padmavathi, "Optimal DG allocation and sizing in a Radial Distribution System using Analytical Approach", International Journal of Science, Engineering and Technology Research (IJSETR), vol. 4, no. 2, (2015).

[4] K. Nadhir, D. Chabane and B. Tarek, "Distributed generation and location and size determination to reduce power losses of a distribution feeder by Firefly Algorithm", International Journal of Advanced Science and Technology, vol. 56, (2013), pp. 61-72.

[5] A. Mohamed Imran and M. Kowsalya, "Optimal size and siting of multiple distributed generators in distribution system using bacterial foraging optimization, Swarm Evolutionary Computer", vol. 15, (2014), pp. 58-65.

[6] D. Rama Prabha and T. Jayabarathi, "Optimal placement and sizing of multiple distributed generating units in distribution networks by invasive weed optimization algorithm", Ain Shams Eng. J., (2015).

[7] M. F. Sulaima, N. F. Napis, M. K. M. Nor, W. M. Dahalan and H. Mokhlis, "DG sizing and DNR based on REPSO for power losses reduction", IEEE 8th International Power Engineering Optimization Conference. (PEOCO), (2014), pp. 99-104.

[8] T. N. Shukla, S. P. Singh and K. B. Naik, "Allocation of optimal distributed generation using GA for minimum system losses in radial distribution networks", International Journal of Engineering, Science and Technology, vol. 2, no. 3, (2010), pp. 94-106.

[9] M. Sedighizadeh and A. Rezazadeh, "Using Genetic Algorithm for Distributed Generation Allocation to Reduce Losses and Improve Voltage Profile", World Academy of Science, Engineering and Technology, (2008).

[10] H. Jalili1, A. Karamizadeh, M. Javad Foroughi, M. Pazhoohesh and M. Jalili, "Optimization of distributed generation location and capacity for improving voltage profile and reducing loss using genetic algorithm (SPEA) with proposing a new index”, Scientific Research and Essays, vol. 6, no. 20, (2011) September 19, pp. 4421-4427.

[11] M. Pushpanjalli and M. S. Sujatha, "A Navel multi-objective under frequency load shedding micro grid using Genetic Algorithm", Inernational Journal of Advanced Research in Electrical, Electronics and Instrumentation Engineering, vol. 4, no. 6, (2015) June.

[12] A. Marimuthu, K. Gnanambal and R. Priyanka, "Optimal allocation and sizing of DG in Radial Distribution System using Whale Optimization Algorithm", IEEE International Conference on Innovations in Green Energy and Healthcare Technologies, (2017).

[13] F. S. Abu-Mouti and M. E. El-Hawary, "Optimal Distributed Generation Allocation and Sizing in Distribution Systems via Artificial Bee Colony Algorithm”, IEEE Transactions On Power Delivery, vol. 26, no. 4, (2011) October.

[14] G. Celli, E. Ghiani, S. Mock and F. Pilo, "A Multi-objective Evolutionary Algorithm for the Sizing and Siting of Distributed Generation”, IEEE Transactions On Power Systems, vol. 20, no. 2, (2005) May.

[15] V. Roja and M. S. Sujatha, "A Review of Optimal Allocation in Distribution System for Loss Minimization”, IOSR Journal of Electrical and Electronics Engineering, (2016), pp. 15-22.

[16] S. Sultana and P. Kumar Roy, "Oppositional krill herd algorithm for optimal location of distributed generator in radial distribution system”, Electr. Power Energy System, vol. 73, (2015), pp. 182-191.

[17] A. Alsaadi and B. Gholami, "An Effective Approach for Distribution System Power Flow Solution", International Journal of Electrical and Computer Engineering, vol. 3, (2009).

[18] J.-H. Ten, "A Direct Approach for Distribution System Load Flow Solutions", IEEE Transactions On Power Delivery, vol. 18, no. 3, (2003) July.

[19] S. N. Sivanandam and S. N. Deepa, "Principles of Soft Computing", Wiley-India Edition, (2008).

[20] A. Hossein Gandomi and A. Hossein Alavi, "Krill herd: A new bio-inspired optimization Algorithm", Commun Nonlinear Sci Numer Simulat, vol. 17, (2012), pp. 4831-4845.

[21] L. Li, Y. Zhou and J. Xie, “A Free Search Krill Herd Algorithm for Functions Optimization”, (2014). 
International Journal of Grid and Distributed Computing

Vol. 11, No. 9 (2018) 